\title{
Water yield responses to climate change and variability across the North-South Transect of Eastern China (NSTEC)
}

\author{
Nan $\mathrm{Lu}^{\mathrm{a}, *}$, Ge Sun ${ }^{\mathrm{b}}$, Xiaoming Feng ${ }^{\mathrm{a}}$, Bojie $\mathrm{Fu}^{\mathrm{a}}$ \\ ${ }^{a}$ Research Center for Eco-Environmental Sciences, Chinese Academy of Sciences, Beijing, China \\ ${ }^{\mathrm{b}}$ Eastern Forest Environmental Threat Assessment Center, U.S. Department of Agriculture Forest Service, Southern Research Station, Raleigh, NC 27606, USA
}

\section{A R T I C L E I N F O}

\section{Article history:}

Received 13 July 2012

Received in revised form 30 November 2012

Accepted 15 December 2012

Available online 25 December 2012

This manuscript was handled by

Konstantine P. Georgakakos, Editor-in-Chief,

with the assistance of Matthew Rodell,

Associate Editor

\section{Keywords:}

NSTEC

Climate change

Evapotranspiration

Water yield

Spatial variability

\begin{abstract}
S U M M A R Y
China is facing a growing water crisis due to climate and land use change, and rise in human water demand across this rapidly developing country. Understanding the spatial and temporal ecohydrologic responses to climate change is critical to sustainable water resource management. We investigated water yield (WY) responses to historical (1981-2000) and projected potential climate changes across a large and complex climatic and land cover gradients over the North-South Transect of Eastern China (NSTEC, a standard terrestrial transect of the International GeoBiological Project, IGBP). After an annual scale evapotranspiration (ET) model was validated with historical streamflow records from ten watersheds, the model was applied to the NSTEC that encompasses seven climatic zones. We found that (1) The spatial and temporal variations of WY were highly dependent on precipitation $(P)$ patterns during 19812000. Overall, the influences of significant temperature $(T)$ rise on the trend of WY were suppressed by the insignificant $P$ change during 1981-2000. (2) The long-term mean WY by climatic zone had a similar pattern as $P$. The different climatic zones had differential contributions to the total volumetric WY of the NSTEC. Within each climatic zone, the volumetric WY for each land cover type was highly dependent on its area of each land cover. (3) Corresponding to the $P$ pattern, the mean WY decreased from the low (South) to high latitude (North), but the rates of changes varied along the NSTEC. Along the NSTEC, the sensitivity of WY to potential $T$ and $P$ changes increased from the high latitude to the low latitude. Future potential changes in WY are likely to follow changes in $P$ with some modification by changes in energy availability. We conclude that precipitation is a major driver for water resource availability, and reliable prediction of future precipitation change patterns is critical to hydrologic forecast across the study region. (c) 2012 Elsevier B.V. All rights reserved.
\end{abstract}

\section{Introduction}

Climate change is hydrologic change (IPCC, 2007). How local water resources will be affected is one of the most important questions in the context of global climate change (Jackson et al., 2001; Gordon and Famiglietti, 2004; Piao et al., 2010). The sign and magnitude of changes in the climatic variables vary by location and time as predicted by IPCC and empirical findings from historical studies (IPCC, 2007; Dang et al., 2007; Lu et al., 2009). Therefore, hydrologic change in response to climate change and variability is expected to be highly variable in space and time, and large uncertainty exists (Davi et al., 2006; Vicuna and Dracup, 2007; Barontini et al., 2009; Zhang et al., 2009). Understanding the spatial and temporal ecohydrological responses to global change is

\footnotetext{
* Corresponding author. Address: State Key Lab. of Urban and Regional Ecology, Research Center for Eco-Environmental Sciences, Chinese Academy of Sciences, Ecology Building RM301, 18 Shuangqing Rd., Beijing 100085, China. Tel./fax: +86 10 62849102.

E-mail address: nanlv@rcees.ac.cn (N. Lu).
}

especially critical to China given the large challenges of water shortage facing this rapidly developing country (Liu and Xia, 2004; Piao et al., 2010).

Regional water resource availability can be well described by water yield (WY) defined as the difference between received precipitation $(P)$ and evapotranspiration (ET), which is a function of many factors including climate, land use and land cover (LULC) (Sun et al., 2002, 2005, 2006). WY represents the maximum water availability for natural ecosystems and human society. Due to the interactions between $P$ and ET and their high spatiotemporal variability, WY is highly variable and likely the most uncertain component in water balance (Barontini et al., 2009). Since $P$ can be measured relatively easily, recent hydrologic studies have focused on ET, a flux that is more difficult/costly to quantify at local, regional and global scales (Fernandes et al., 2007; Gao et al., 2007; Jung et al., 2010; Sun et al., 2011; Bing et al., 2012). According to the Clausius-Clapeyron relationship that specific humidity increases approximately exponentially with temperature, the global water cycle is accelerating due to the rising temperatures increase ET rates (Huntington, 2006; Meehl et al., 2007; Zhang et al., 2009). 
However, there are no clear signals of global scale WY changes (IPCC, 2007; Bates et al., 2008) and changes of $P$ at local scale are even more variable. Previous WY studies have found both increasing and decreasing trends in the 20th century (Wang et al., 2008; Peng and Xu, 2009; López-Moreno et al., 2011). The inconsistent findings among studies may be due to the differences in scale, climate conditions, LULC, study period, analysis methods, and the magnitude of climate change.

Studies that use a uniform method to detect the potential differences in hydrologic changes across an environmental gradient can provide insight of climatic change impacts on water resources (Rosenberg et al., 2003; Serrat-Capdevila et al., 2011). Multi-scale analysis of hydrologic response to climate change is fundamental to understanding the mechanisms that drive climate-water resource interactions (Blöschl, 2006; Wagener et al., 2010). In this study, we examined the potential WY response to climate change at site and zonal scales along the latitudinal gradient in the North-South Transect of Eastern China (NSTEC). The NSTEC is one of the fifteen standard terrestrial transects of IGBP. It is a rare transect that encompasses a large climate gradient spanning from temperate to tropical climate that support many unique ecosystems. Thus, the NSTEC is an ideal experimental field for studying hydrological responses under a changing climate. Understanding the hydrologic cycles and key control factors across a transect gradient is one of the major goals of the IGBP Terrestrial Transects studies (Koch et al., 1995).

Specifically, our objectives were: (1) to quantify the historic trends and its spatial variability of WY at station and climatic zonal scales across the NSTEC during 1981-2000, (2) to examine the spatial pattern in long-term WY across the climatic zones and among different LULC types, and (3) to examine the WY sensitivity to temperature and precipitation changes along the latitudinal gradient of the NSTEC.

\section{Methods}

The NSTEC has large climatic variability and complex LULC characteristics (Figs. 1 and 2). Estimates of annual WY at all scales (watershed, station, and regional) were based on annual water balance principles. We first evaluated the model performance for estimating WY by comparing measured streamflow from ten large watersheds across the NSTEC and modeled WY. The historical trend of $\mathrm{WY}$ was evaluated at both site and regional (or climatic zonal) scales, where the observed climate data from the 281 meteorological stations and the grid-based spatial extrapolations were used, respectively. The long-term WY and its sensitivity to defined climate scenarios were evaluated with the focus of analysis on the spatial patterns along the latitudinal profile.

\subsection{The NSTEC}

The NSTEC covers approximately $29 \%$ of land area of China with longitude ranging from $108^{\circ}$ to $118^{\circ} \mathrm{E}$ for latitude less than $40^{\circ} \mathrm{N}$, and ranging from $118^{\circ}$ to $128^{\circ} \mathrm{E}$ for latitude greater than $40^{\circ} \mathrm{N}$. The annual mean air temperature $(T)$ increases gradually along the latitudinal gradient with the rate of $0.8^{\circ} \mathrm{C}$ per $1^{\circ}$ latitude (Fig. 1a). The annual $P$ increases $\sim 17 \mathrm{~mm}$ per $1^{\circ}$ latitude above $40^{\circ}$ and $\sim 72 \mathrm{~mm}$ per $1^{\circ}$ latitude below $40^{\circ}$ along the latitudinal gradient. The annual mean potential evapotranspiration (PET) to $P$ ratio, a dryness index, is generally increasing from the low to high latitude with the region of latitude $36-40^{\circ}$ having the highest dryness (Fig. 1b). According to the climate classification system of the Climatological Atlas of the People's Republic of China (1979), the NSTEC spans over seven major climatic zones from the north to the south including North Temperate Zone (Ntemp), Middle Temperate Zone (Mtemp), South Temperate Zone (Stemp), North Subtropical Zone (Nsubtrop), Middle Subtropical Zone (Msubtrop), South Subtropical Zone (Ssubtrop), and North Tropic Zone (Ntrop).

Complex natural vegetation develops as a result of the energy and water distributions across the latitudinal gradient. However, the natural vegetation has been greatly modified into other land use types, particularly to croplands, due to thousands of years of human inhabitation in eastern China (Fig. 2a). According to the Chinese Academy of Sciences land use classification (CAS1990 system), the LULC data had 6 first-class and 25 second-class classification types based on Landsat MSS, TM and ETM imageries and (a)

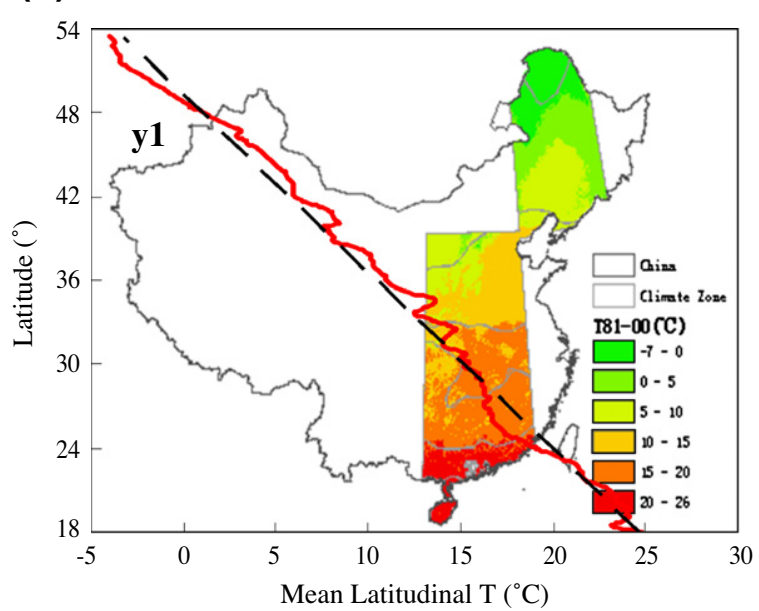

(b)

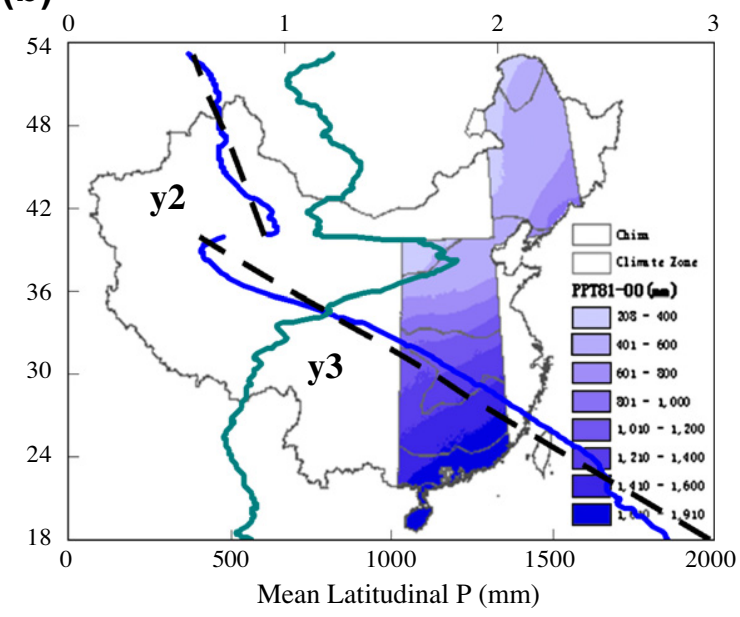

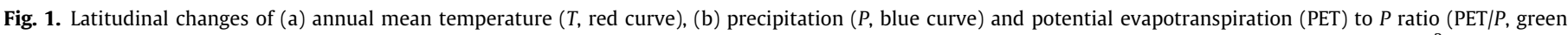

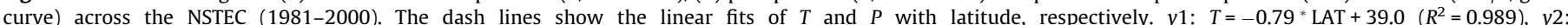

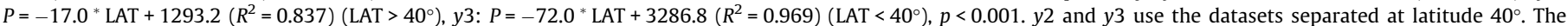

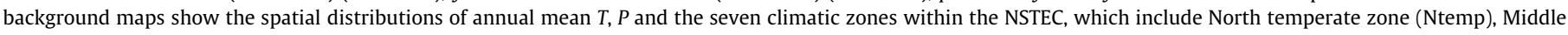

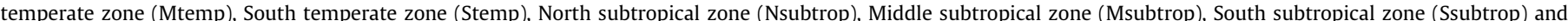

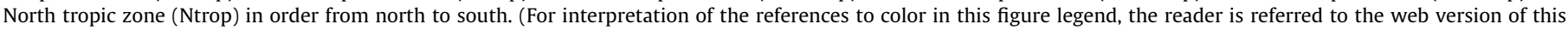
article.) 
(a)
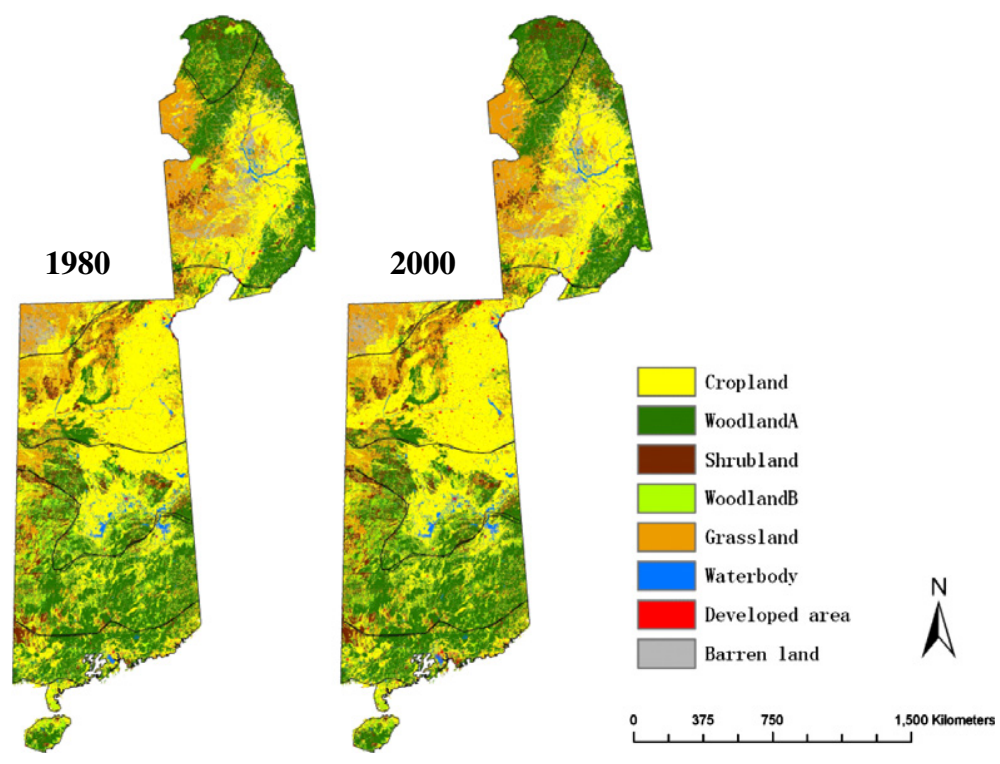

(b)

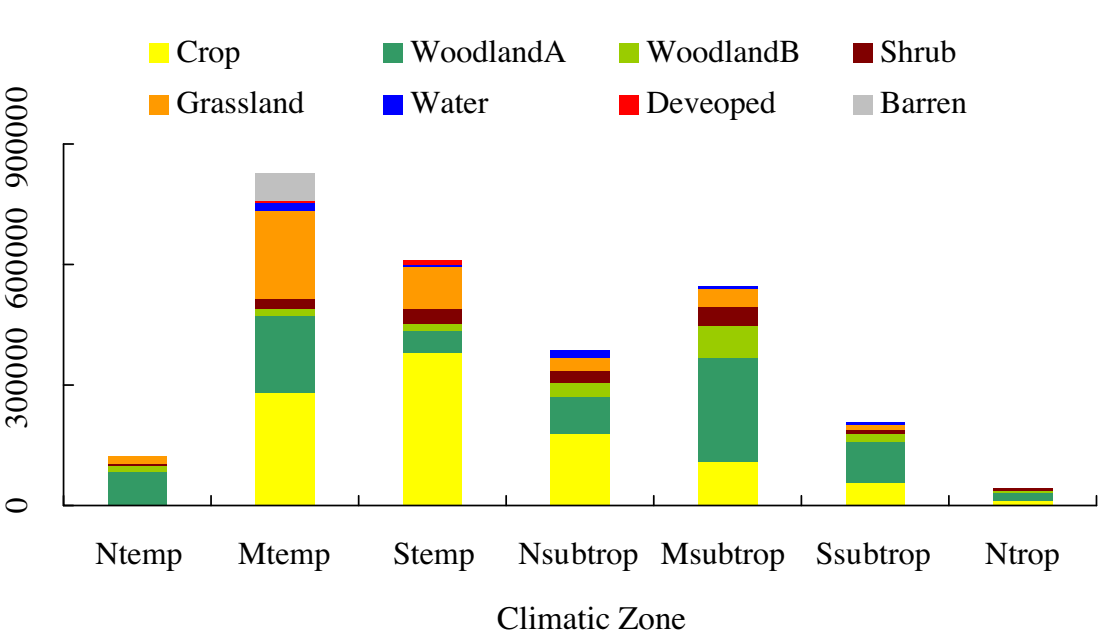

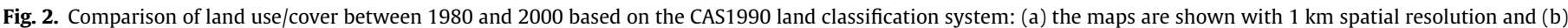
accumulated area of constant LULC types between 1980 and 2000 in each climatic zone.

expert interpretation ( $1 \mathrm{~km}$ resolution) (Ran et al., 2009). For the consideration of model application in this study, the second-class classification were re-combined into eight classes including cropland, woodland A (forest cover $>30 \%$ ), woodland B (forest cover $<30 \%$ ), shrub land, grassland, water body, developed area, and barren land (Fig. 2a). Cropland and woodland were the dominant LULC types, covering $36.9 \%$ and $36.4 \%$ of the NSTEC area, respectively. Grassland was about $15.3 \%$ of the NSTEC and other LULC types were all less than $10 \%$. Different LULC types were unevenly distributed across the NSTEC with cropland mainly covering the Mtemp and Stemp zones and having the largest fraction in the Stemp zone. In contrast, woodland had the largest fraction of coverage in the Ntemp zone and the Msubtrop zone. Grassland had the largest fraction of coverage in the Mtemp zone (Fig. 2b).

\subsection{Water yield (WY) model development}

We define WY as: $W Y=P$ - ET with an assumption that the change in soil water storage is negligible at the annual time scale. To calculate WY, we used locally measured $P$, and mathematically modeled ET as a function of PET, $P$, and vegetation characteristics (Zhang et al., 2001). The same water balance equation was used for estimating WY at watershed, station, and regional scale.

Annual ET was estimated using the empirical model by Zhang et al. (2001), expressed as

$\mathrm{ET}=\frac{1+w \frac{\mathrm{PET}}{P}}{1+w \frac{\mathrm{PET}}{P}+\left(\frac{\mathrm{PET}}{P}\right)^{-1}} \cdot P$

where annual PET was calculated by summing of monthly PET using the Hamon method (Federer and Lash, 1978), for which the required variables include monthly $T$ and daytime length. Daytime length was calculated as a function of latitude. The values for plantavailable water coefficient, $w$ parameter, were determined by LULC types. We acquired monthly $T$ and $P$ data from 281 standard meteorological stations that were relatively evenly distributed in the NSTEC (China Meteorological Data Sharing Service System, http:// www.cdc.cma.gov.cn/). We also acquired regional gridded $T$ and $P$ data ( $1 \mathrm{~km}$ spatial resolution) from the Chinese Natural Resources Database (http://www.data.ac.cn/). 

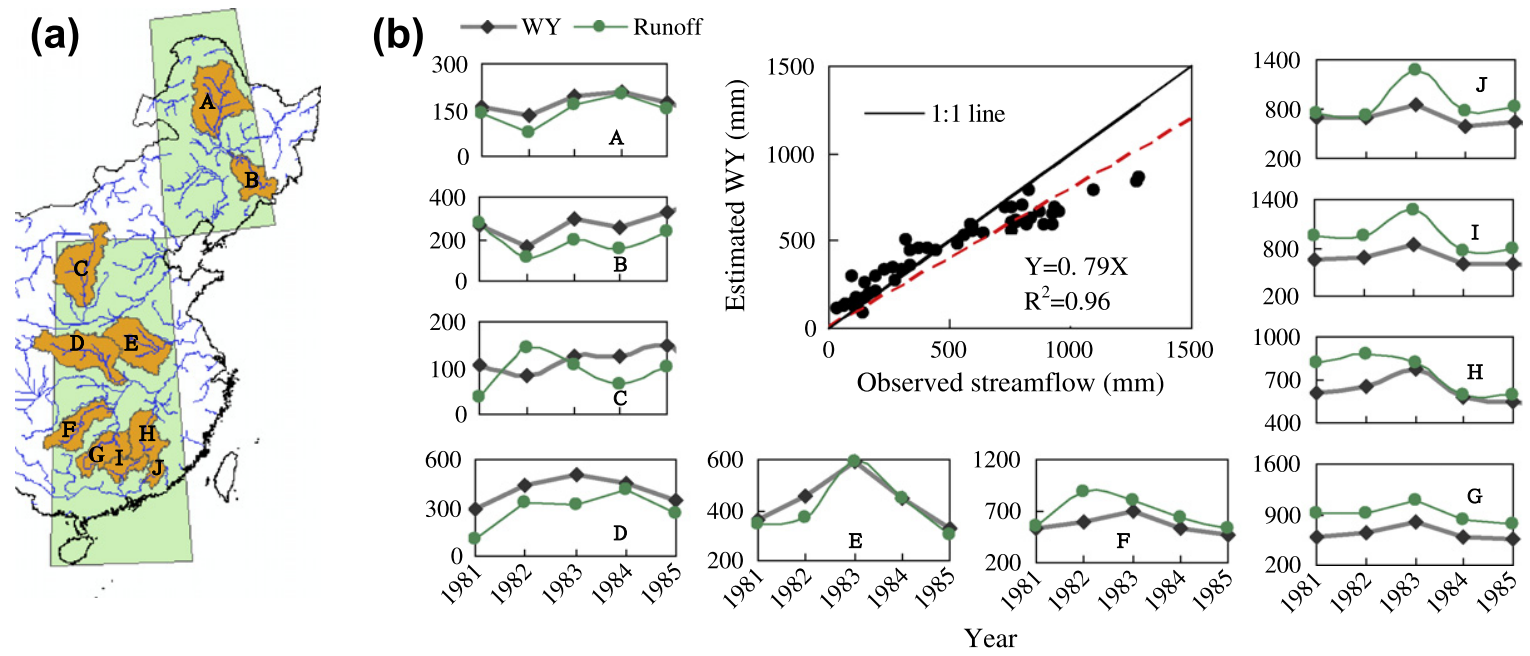

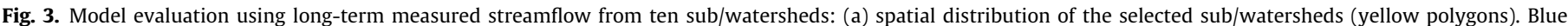

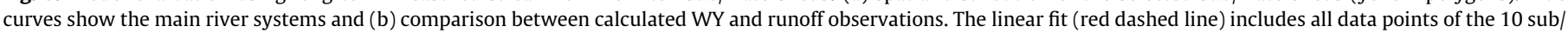

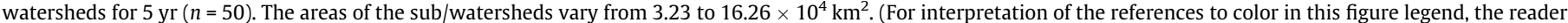
is referred to the web version of this article.)

Zhang et al. (2001)'s ET model has been used and validated in a few studies (Sun et al., 2005, 2006; Liu and Yang, 2010), and these studies suggest the model offers a reliable tool to evaluate regional water yield over a long time frame. The empirical method is simple to apply to a large area to quantify the effects of climate change on ET and thus water yield at varied spatial scales (Liu and Yang, 2010).

According to the published literatures in China (Sun et al., 2002, 2006) and elsewhere (Zhang et al., 2001), the w parameter values were assigned as 0.5 for cropland, 2.0 for high-cover woodland (where forest cover $>30 \%$ ), 1.0 for low-cover woodland (where forest cover <30\%), 1.0 for shrubland and 0.5 for grassland, 0.1 for developed and barren land in this study. For water body, ET was defined as the minimum of $P$ and PET, i.e., ET $=\operatorname{Min}(P$, PET $)$. We assumed that there were no changes in LULC types during the period of 1980-2000. The areas that had different LULC types between 1980 and 2000 were excluded ( $<5 \%$ of total area) from the analysis to eliminate the hydrological changes caused by LULC alteration. The performance of the ET model was evaluated with hydrologic records from 10 large watersheds across the NSTEC (Fig. 3a) before it was applied to the study region using a GIS operation. The streamflow data were obtained from the Data Sharing Infrastructure of Earth System Science (DSIESS, http://www.geodata.cn) (data available for 1981-1985).

\subsection{Sensitivity analysis}

The sensitivities of WY responses to $T$ or $P$ change were tested by increasing and decreasing $T$ or $P$ to certain magnitudes. $T$ was increased or decreased by $1^{\circ} \mathrm{C}$ or $2{ }^{\circ} \mathrm{C}$ from the baseline, respectively, with no change in $P$. Similarly, $P$ was increased or decreased by $10 \%$ and $20 \%$, respectively, with no change in $T$. The $2{ }^{\circ} \mathrm{C}$ increase in $T$ is regarded as the threshold of "dangerous" climate change because many irreversible changes will occur for the earth system (Todd et al., 2010). These hypothetical scenarios were set to mimic the mean ranges of climatic change projected in Global Circulation Models (GCMs) for China. For example, the CGCM3 and HADCM2 projections suggest that, across NSTEC by $2050, T$ may change -4 to $2{ }^{\circ} \mathrm{C}$ and $P$ change $-50 \%$ to $50 \%$ along the latitudinal profile (data from the DSIESS). We did not use the projections of global scale circulation models (GCMs) due to great uncertainty in future emissions of greenhouse gases, their translation into climate forcing and changes, and the translation of the climate changes by the
GCMs to our study region (Arnell, 1999). Essentially, we were interested in the differential sensitivity of WY across the study region.

\section{Results}

\subsection{Model validation}

The modeled WY compared well to measured streamflow (modeled $\mathrm{WY}=0.79 \times$ Measured, $n=50, R^{2}=0.96, \quad p<0.0001$, $\mathrm{RMSE}=104 \mathrm{~mm} / \mathrm{yr}$ ). The annual variations of $\mathrm{WY}$ were generally synchronous in the ten selected watersheds (Fig. 3b). Underestimations of WY were found in the southern region $(\mathrm{G}, \mathrm{H}, \mathrm{I}$, and $\mathrm{J})$, indicating an overestimation of ET in the southern region. Overall, the modeling accuracy was somewhat higher than similar studies at the national scale (Sun et al., 2006). The 5-yr mean measured streamflow ranged from 91 to $939 \mathrm{~mm}$ and the mean simulated WY ranged from 119 to $693 \mathrm{~mm}$ across the ten watersheds. The ratio of $\mathrm{WY} / P$ ranged from 0.28 to 0.42 across the ten watersheds.

\subsection{Historical changes in $W Y$ at site and zonal scales}

\subsubsection{Site scale}

At the site scale, temporal trends in the climatic and hydrological variables including annual mean $T$, annual $P$, PET, ET, and WY were quantified at the 281 meteorological stations within the seven climatic zones in the NSTEC from 1981 to 2000. The results showed that $T$ had increasing trends at 276 stations (98.2\%) across the NSTEC, and $232(77.9 \%)$ of them were statistically significant with the magnitudes of trends varying from 0.026 to $0.260{ }^{\circ} \mathrm{C} / \mathrm{yr}$ $(p<0.05)$. Similarly, most of the stations $(93.8 \%)$ showed increasing trend in annual PET, and $63 \%$ of them were statistically significant. In terms of $P, 133$ (47.3\%) of the sites had increasing trends and 148 $(52.7 \%)$ of the sites had decreasing trends in the same period. However, the $P$ trends were significant at only 19 sites with 7 increasing and 12 decreasing trends, respectively. In other words, $P$ had no significant changes in most of the station sites during 19812000. The trend of modeled ET was similar to P. During 19812000, 141 stations (53\%) had increasing and 140 stations (47\%) had decreasing trends in annual ET, and only 23 of them were significant, with 16 increasing and 7 decreasing ones (range from -8.3 to $8.6 \mathrm{~mm} / \mathrm{yr}, p<0.05)$, respectively. 
Table 1

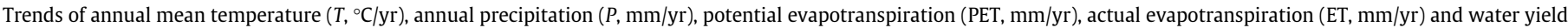
(WY, mm/yr) from 1981 to 2000 at site scale. The table only showed the 23 sites where had significant trends $(p<0.05)$ for WY. NS: not significant.

\begin{tabular}{|c|c|c|c|c|c|c|c|c|c|c|c|c|c|}
\hline Zone & ID & PPT & $T$ & PET & ET & WY & Zone & ID & PPT & $T$ & PET & ET & WY \\
\hline \multirow[t]{3}{*}{ Mtemp } & 1 & -11.0 & 0.051 & 2.9 & NS & -8.0 & Nsubtrop & 13 & -20.3 & 0.078 & 6.2 & -8.3 & -12.0 \\
\hline & 2 & NS & 0.060 & 3.7 & NS & -3.1 & & 14 & -15.0 & 0.050 & 6.6 & NS & -9.6 \\
\hline & 3 & NS & 0.066 & 4.3 & NS & -1.2 & & 15 & -12.0 & 0.046 & 5.1 & -6.4 & -5.6 \\
\hline \multirow[t]{9}{*}{ Stemp } & 4 & -13.9 & 0.065 & 3.4 & NS & -11.2 & & 16 & 23.1 & 0.043 & 3.4 & 8.5 & 14.6 \\
\hline & 5 & -13.3 & 0.069 & 6.6 & -7.7 & -5.6 & & 17 & 23.8 & NS & NS & 8.6 & 15.2 \\
\hline & 6 & -9.8 & 0.091 & 6.3 & -5.5 & -4.2 & & 18 & 24.5 & 0.011 & -1.2 & 6.2 & 18.4 \\
\hline & 7 & -8.8 & 0.060 & 4.9 & -5.7 & -3.2 & Msubtrop & 19 & -28.6 & 0.036 & 2.1 & $N S$ & -27.8 \\
\hline & 8 & -8.8 & 0.059 & 4.6 & -6.2 & -2.6 & & 20 & 16.9 & NS & NS & 7.0 & 9.9 \\
\hline & 9 & NS & 0.256 & 9.6 & 3.0 & -14.1 & & 21 & 21.5 & 0.055 & 3.4 & 7.3 & 14.2 \\
\hline & 10 & $N S$ & 0.073 & 4.9 & $N S$ & -6.4 & & 22 & 29.9 & 0.044 & 2.5 & 7.7 & 22.1 \\
\hline & 11 & NS & 0.044 & 5.1 & NS & -4.4 & Ssubtrop & 23 & $N S$ & 0.042 & 4.6 & NS & -11.7 \\
\hline & 12 & NS & 0.053 & 4.5 & NS & 3.1 & & & & & & & \\
\hline
\end{tabular}

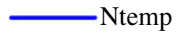

(a)

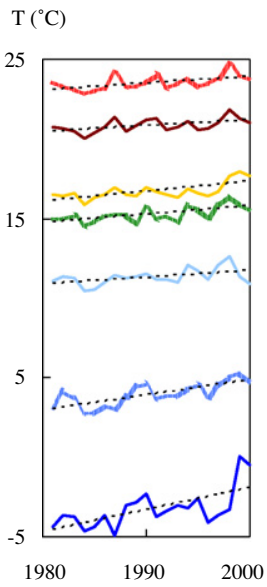

(b)

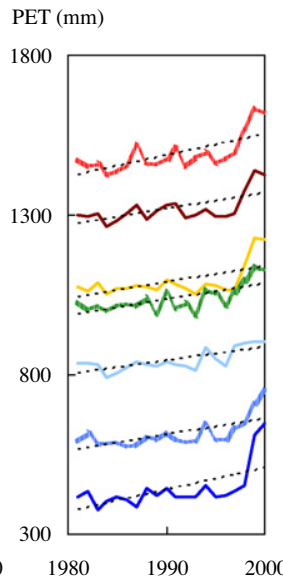

-Stemp

(c)

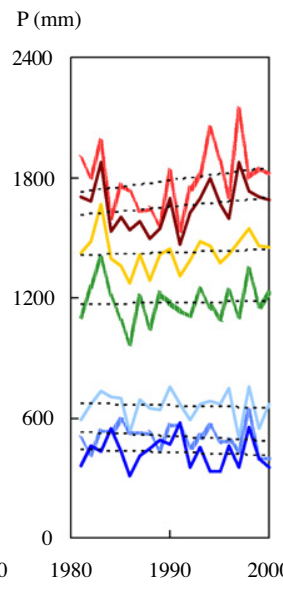

(d)

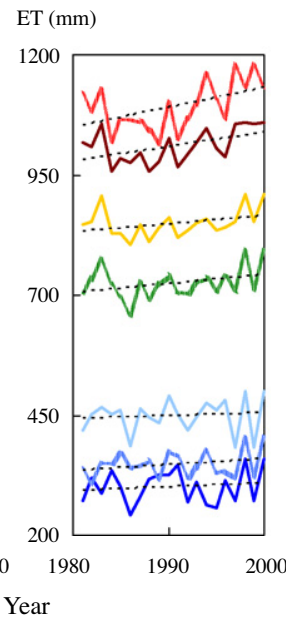

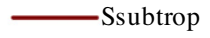

(e)

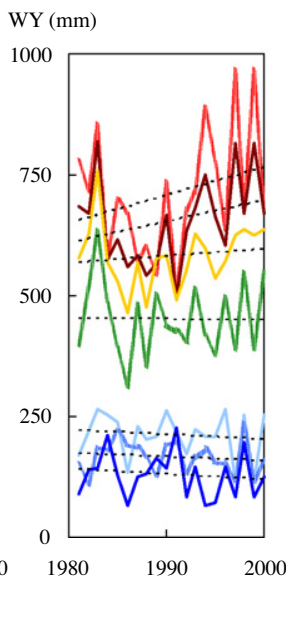

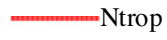

(f)

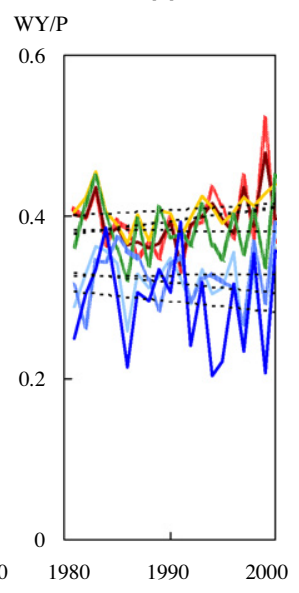

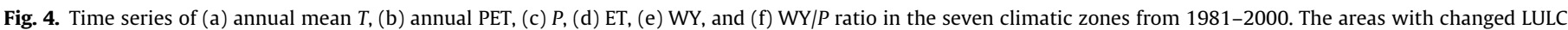

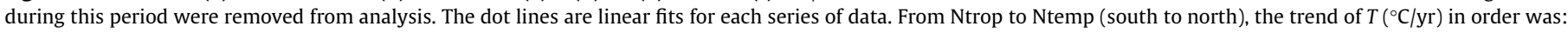

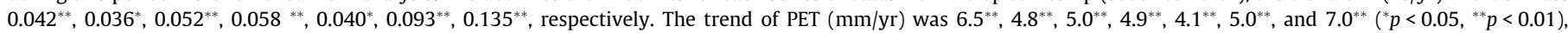

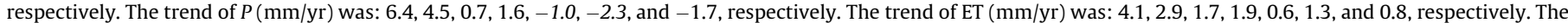
trend of WY $(\mathrm{mm} / \mathrm{yr})$ was: $5.8,4.4,1.5,-0.07,-0.10,0.4$, and -0.09 , respectively. All the trends for $P$, ET, WY and WY/P ratio were insignificant at $p$ level of 0.05 .

Regarding WY, we found that 109 stations (42.3\%) and 172 stations $(57.7 \%)$ had increasing and decreasing trends, respectively. Only 7 increasing and 16 decreasing trends were significant $(p<0.05)$. The sites with significant changes reflected the maximum WY change ( -27.8 to $22.1 \mathrm{~mm} / \mathrm{yr}$ ) during the 20 -yr period. It is worthy to note that the 17 sites with significant $P$ trends accounted for $69.6 \%$ and $56.5 \%$ of the stations where ET or WY had significant trends, respectively (Table 1 ). This suggested that when $P$ increased, increases in WY occurred even though ET increased as well, and vice versa. The consistent smaller changes in WY compared to $P$ reflected the modification of ET. $T$ may only significantly influence WY trends at few sites. Besides, the trends of WY of the individual stations were significantly correlated with the $P$ trends $\left(R^{2}=0.82, p<0.01, n=281\right)$ but not correlating with the trends of $T$. These findings revealed that the variations of WY were mainly dependent on $P$, and the potential effects of $T$ were mostly masked by $P$ during the study period.

\subsubsection{Zonal scale}

The zonal scale analysis was based on grid cell calculations for the seven climatic zones within the NSTEC. During the period of 1981-2000, both the zonal mean $T$ and PET increased significantly in all of the climatic zones ( $p<0.05$, Fig. $4 \mathrm{a}$ and $\mathrm{b}$ ). The zonal mean annual $P$ showed increasing trends in the three subtropical zones and the Ntrop zone and decreasing trends in the three temperate zones, but the trends in $P$ were not significant in any of the zones (Fig. 4c).

The trend of WY at the climate zone scale had a different pattern. The zonal mean annual WY showed increasing trends in Mtemp, Msubtrop, Ssubtrop and Ntrop zones, and decreasing trends in Ntemp, Stemp, Nsubtrop zones, respectively (Fig. 4e). However, none of the WY trends were statistically significant, and the same to the WY/P ratio (Fig. 4f). The effects of $T$ on WY were suppressed by the insignificant annual $P$ trends because the unchanged $P$ restricted the increase of ET (Fig. $4 \mathrm{~d}$ ). The magnitude of significant trends at the zonal scale for WY $(-0.1$ to $5.8 \mathrm{~mm} / \mathrm{yr})$ were much lower than those at the site level, reflecting the masking effects of larger over smaller scale variations of climatic variables.

\subsection{Spatial viability in long-term mean WY: among climatic zones and LULC types}

The estimated mean annual ET for the NSTEC region was $588 \mathrm{~mm}$. The mean annual WY during 1981-2000 across the NSTEC was $344 \mathrm{~mm}$, ranging from $132 \mathrm{~mm}$ in Ntemp to $711 \mathrm{~mm}$ 
(a)
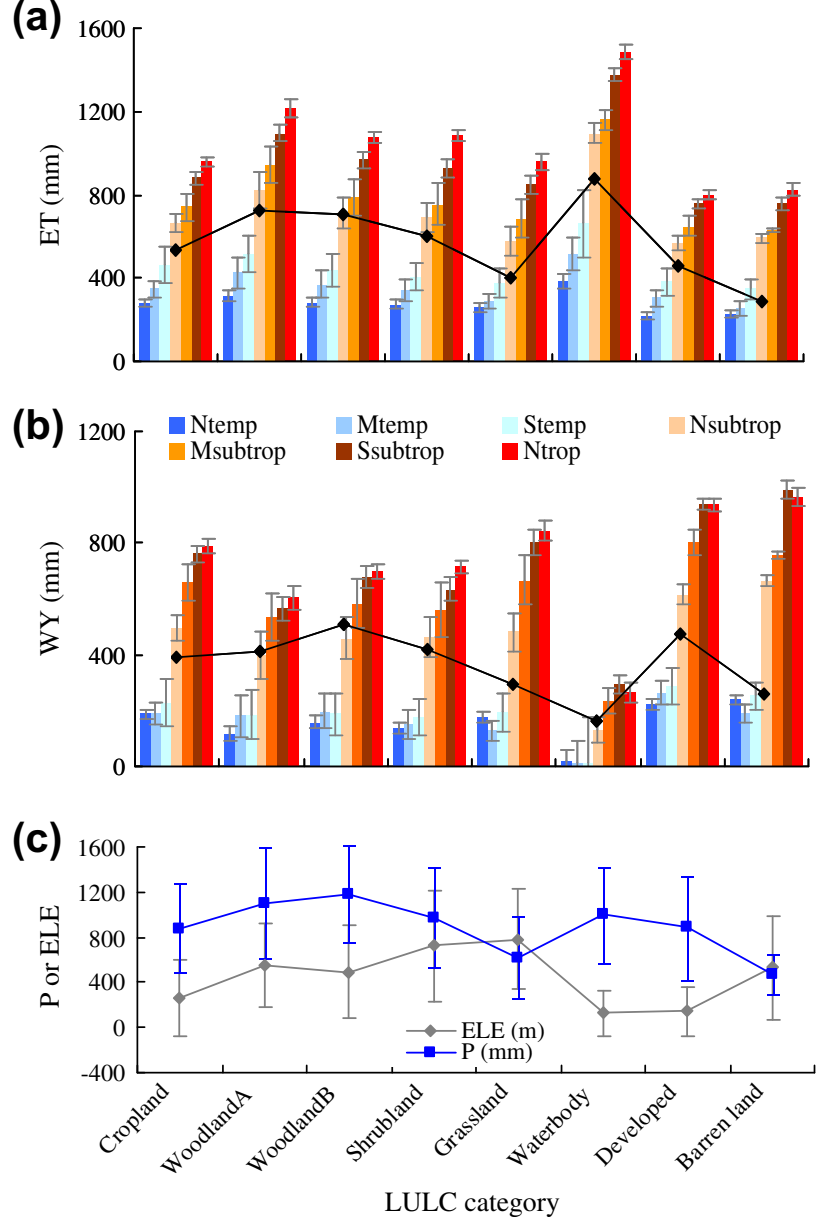

Fig. 5. Comparison of long-term mean (a) ET, (b) WY, (c) $P$ and elevation (ELE) among climatic zones for diffident LULC types from 1981 to 2000. The black dots represent the mean ET or WY for each LULC type across the climatic zones. The blue squares represent the mean $P$. WoodlandA: woodland with forest cover $>30 \%$, woodlandB: woodland with forest cover $<30 \%$. Error bars are standard deviations. (For interpretation of the references to color in this figure legend, the reader is referred to the web version of this article.)

in Ntrop. As expected, ET increased from the high latitude to the low latitude corresponding to the general climatic gradients (Fig. 5a). Generally, WY also increased from the Ntemp to the Ntrop zone regardless of LULC types (Fig. 5b). Thus, the spatial WY patterns of increasing from Ntemp to Ntrop were mostly a result of overwhelming influences of $P$ over ET.

We found that the mean ET was highest in high-cover woodland (733 mm), followed by low-cover woodland $(708 \mathrm{~mm})$, shrubland (597 $\mathrm{mm})$, cropland $(527 \mathrm{~mm})$ and grassland $(382 \mathrm{~mm})$ in the vegetated LULC types in the NSTEC (Fig. 5a). At the same time, the mean $P$ was highest in high-covered woodland, and then lowcovered woodland, followed by shrubland, cropland and grassland (Fig. 5c). As the outcome of the interactions between $P$ and ET, the mean WY was highest in low-covered woodland $(478 \mathrm{~mm})$, and then shrub land $(380 \mathrm{~mm})$, high-covered woodland $(370 \mathrm{~mm})$, cropland $(349 \mathrm{~mm})$ and grassland $(240 \mathrm{~mm})$. Water body had the lowest WY value $(105 \mathrm{~mm})$ among all LULC types due to highest ET ( $891 \mathrm{~mm}$ ) but moderate $P$ (Fig. $5 \mathrm{~b}$ ).

In order to quantify the differences in water supply among different LULC types and climatic conditions, the volumetric WY for each LULC type and climate zone was calculated. The long-term mean volumetric WY was $926 \times 10^{9} \mathrm{~m}^{3}$ in the entire NSTEC area (accounting for $34.1 \%$ of total surface water in China). Notably, different climatic zones had varied contributions to the total water resources of the NSTEC not solely depending on the sizes of the zones (Figs. 6a and 2b). The Msubtrop had the highest WY followed by the Nsubtrop and the Ssubtrop, and the Stemp and the Mtemp had similar contributions. The magnitude of $P$ among the climatic zones should be the main cause of the differences in total volumetric water. Whereas, the small volumetric WY in Ntemp and Ntrop were indeed due to small areas.

However, within each climatic zone, the contribution of each LULC type to the zonal total WY was highly dependent on its fractional area (Fig. 6b). This suggested that at large scales the differences in volumetric WY among LULC types were mainly caused by the area of coverage, and the effect of the differences in WY per unit area among LULC types was relatively small in the NSTEC.

\subsection{The pattern of $W Y$ and its sensitivity to $T$ and $P$ changes along the latitudinal profile}

Along the latitudinal gradient, the long-term WY showed a general decreasing trend from the south to the north (Fig. 7a). However, there appeared two remarkable breaking points along the curve. The turning points were caused by the westwards shift or retraction of the right boundary of the NSTEC at $40^{\circ}$ (due to the transect definition) and $\sim 20.75^{\circ}$ (the location of the Taiwan Island), respectively. The rates of change in WY with latitude were not identical but decreased from $34.6 \mathrm{~mm}$ to $7.6 \mathrm{~mm}$ above and below $40^{\circ}$ ( $\sim 5$ times of difference). This may be caused by the $10^{\circ}$ shift of the transect boundary away from the sea at $40^{\circ}$ caused a decreasing $P$. When regressing the latitudinal gradient into $P$ and $T$ gradients, we found that WY was linearly correlated with $P$ with the rate of $0.43 \mathrm{~mm}$ per $\mathrm{mm} P\left(R^{2}=0.99, p<0.001\right)$; but it was correlated with $T$ in a significantly nonlinear fashion
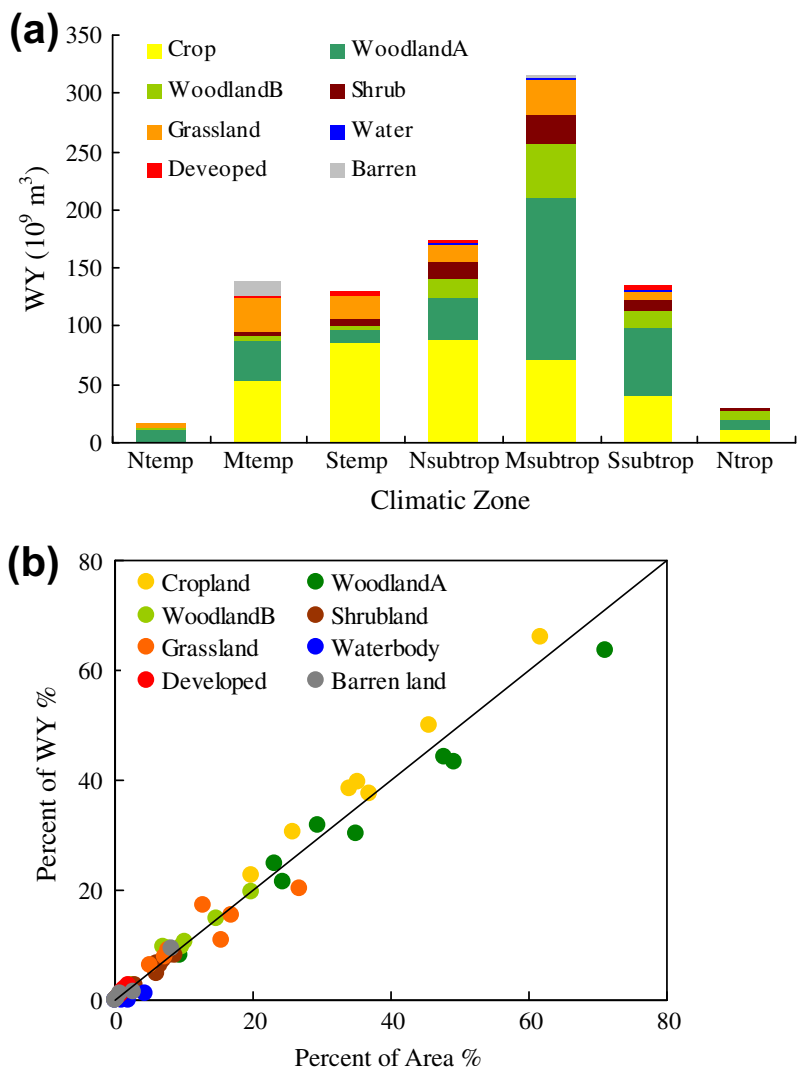

Fig. 6. Volumetric WY of different LULC types: (a) accumulated volumetric WY of different LULC types in each of the climatic zones and (b) linear correlation of the percent of water volume with the percent of area for different LULC types. 

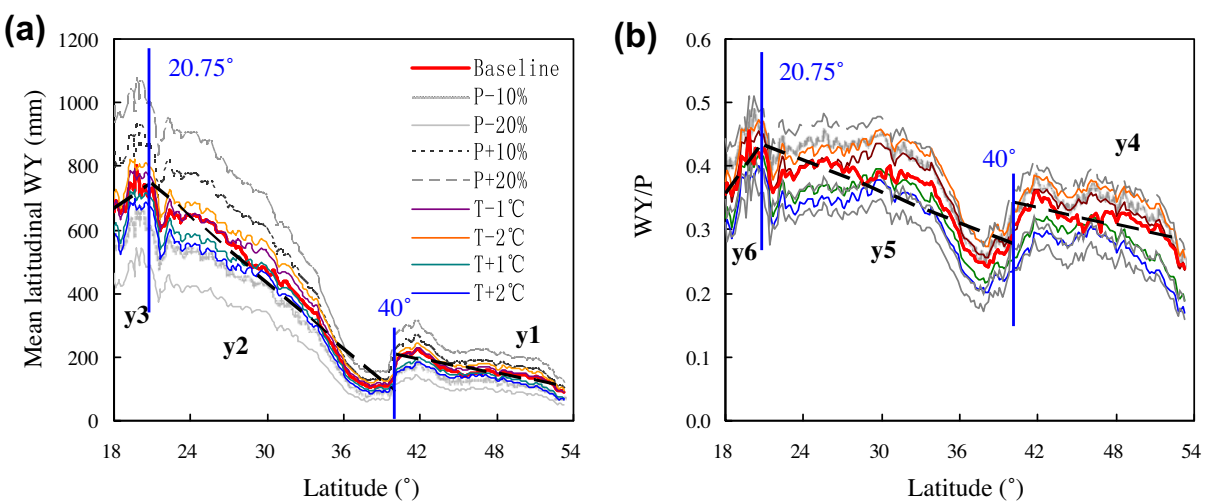

Fig. 7. Spatial patterns of long-term (a) WY and (b) WY/P ratio and their responses to specified precipitation and temperature changes $\left(T \pm 1{ }^{\circ} \mathrm{C}, T \pm 2{ }^{\circ} \mathrm{C}, P \pm 10 \%, P \pm 20 \%\right.$ ) along the latitudinal NSTEC. The red curves (baseline) mean long-term averages from 1981 to 2000 for climate and constant LULC types during this period. The dash lines are linear fits of long-term WY or WY $/ P$ with latitude (LAT), separated at $40^{\circ}$ and $20.75^{\circ}$, respectively. $y 1$ : WY $=-7.6^{*} \mathrm{LAT}+511.1\left(R^{2}=0.822\right)\left(\mathrm{LAT}>40^{\circ}\right), y 2$ : $\mathrm{WY}=-34.6^{*} \mathrm{LAT}+1471.7 \quad\left(R^{2}=0.954\right) \quad\left(20.75^{\circ}<\mathrm{LAT}<40^{\circ}\right), \quad y 3: \quad \mathrm{WY}=28.4^{*} \mathrm{LAT}+157.3 \quad\left(R^{2}=0.374\right) \quad\left(\mathrm{LAT}<20.75^{\circ}\right), \quad y 4: \quad \mathrm{WY}=-0.005^{*} \mathrm{LAT}+0.533 \quad\left(R^{2}=0.54\right), \quad y 5:$ $\mathrm{WY}=-0.008 * \mathrm{LAT}+0.601\left(R^{2}=0.68\right), y 6: \mathrm{WY}=0.029 * \mathrm{LAT}-0.157\left(R^{2}=0.66\right), p<0.001$. (For interpretation of the references to color in this figure legend, the reader is referred to the web version of this article.)

Table 2

Changes in WY responding to $T$ or $P$ projections in the entire NSTEC.

\begin{tabular}{|c|c|c|c|c|c|c|c|c|}
\hline & $T-1{ }^{\circ} \mathrm{C}$ & $T-2{ }^{\circ} \mathrm{C}$ & $T+1^{\circ} \mathrm{C}$ & $\mathrm{T}+2^{\circ} \mathrm{C}$ & $P-10 \%$ & $P-20 \%$ & $P+10 \%$ & $P+20 \%$ \\
\hline$\Delta \mathrm{WY}(\mathrm{mm})$ & 15.6 & 34.5 & -23.1 & -41.9 & -60.7 & -119.4 & 69.2 & 139.9 \\
\hline $\begin{array}{l}\Delta \mathrm{WY} / \mathrm{WY}_{\text {baseline }}(\%) \\
\mathrm{WY} \mathrm{Y}_{\text {baseline }}=343.7 \mathrm{~mm}\end{array}$ & 4.5 & 10.0 & -6.7 & -12.2 & -17.7 & -34.7 & 20.1 & 40.7 \\
\hline
\end{tabular}
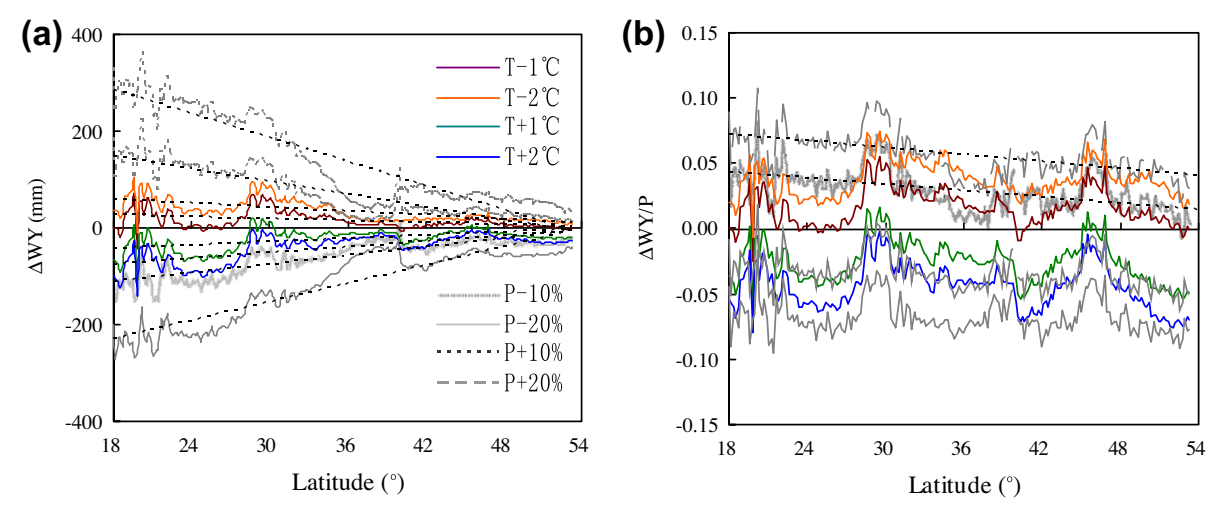

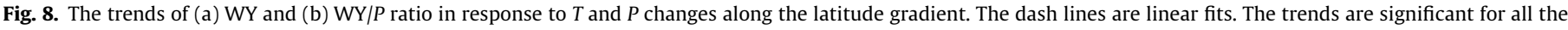
scenarios for the response of $\mathrm{WY}(\Delta \mathrm{WY})$, but only significant for $(P+10 \%)$ and $(P+20 \%)$ scenarios for the response of WY/P ratio $(\Delta W Y / P)$ at $p$ level of 0.05 .

$\left(\mathrm{WY}=0.98 T^{2}+4.25 T+117.15, R^{2}=0.99, p<0.001\right)$. Similarly, the long-term $W Y / P$ ratio showed the same decreasing pattern as that of WY from the south to the north along the transect (Fig. 7b). However, the differences between the rates of change in different geographical areas were smaller than those of absolute WY.

For the entire NSTEC, WY decreased by $6.7 \%$ and increased by $4.5 \%$ compared to the baseline when increasing and decreasing $1{ }^{\circ} \mathrm{C}$, respectively (Table 2 ). The percent changes of WY caused by the defined $P$ variations (10\% and 20\%) were much higher than those caused by $T$, indicating high sensitivity of WY to $P$ variations. Along the latitudinal gradient, WY changes $(\Delta \mathrm{WY}, \mathrm{mm})$ due to $T$ or $P$ changes tended to decrease from lower (south) to higher (north) latitudes (Fig. 8a). This means that when changing $T$ by the same magnitude or $P$ by the same fraction, the dry northern part of the NSTEC tended to have smaller absolute changes in WY than the humid southern part. Similarly, the change of WY/P ratio had significantly negative correlation with latitude when increasing $P$ for $10 \%$ or $20 \%$. Whereas, the change of $\mathrm{WY} / P$ ratio due to $P$ decrease or $T$ variations (increase or decrease) was not significantly correlated with latitude (Fig. 8b).

\section{Discussion}

\subsection{Historical trends of ET, PET, and WY}

A comprehensive interpretation of WY depends on good understandings in all components of the hydrologic cycle and their interactions. Herein, $P$ is directly measured and has least uncertainty, while ET and its relationship with PET are less confined and quantifying the trends of these two variables can be problematic and confusing sometimes. For example, there are many methods that can estimate PET either based on temperature or many other climatic variables (Lu et al., 2003). For convenience, Pan evaporation (Pan E) is often used to represent PET. However, recent studies suggest that Pan E can have opposite trend to actual ET and PET that 
are estimated based on climatic data. The relationship between decreasing trend of Pan E and increasing trend of temperature (or PET), the so called "pan evaporation paradox", is not contradictory but actually complementary (Brutsaert and Parlange, 1998; Hobbins et al., 2004). The decreasing trend of Pan E found in most areas of China and many other countries worldwide in past decades confirmed this theory (Peterson et al., 1995; Qiu et al., 2003; Ren and Guo, 2006). Pan E may have been used in climate change studies incorrectly since it can be regarded as a good proxy of PET only in humid environments.

Our finding for site scale ET trend was comparable to the findings from Zhou et al. (2009). They reported that $40 \%$ area of China showed a decreasing trend in ET with the magnitude range from -5 to $-10 \mathrm{~mm} / \mathrm{yr}$ in the majority of areas, and the increasing trend was up to $20 \mathrm{~mm} / \mathrm{yr}$ from 1991 to 2000 . However, our study suggested that the ET change rates were higher than another study by Gao et al. (2007) which reported that the ET trends varied from -3 to $2 \mathrm{~mm} / \mathrm{yr}$ at 686 meteorological stations across entire China during 1961-2002. The differences in the sign and magnitude of trends among studies are partly related to the different time window.

The results of insignificant $\mathrm{WY}$ trends at most of the stations (92\%) and all the climatic zones were consistent with other studies that the past magnitude of variations in annual mean $T$ were not high enough to cause significant change in annual streamflow (Gordon and Famiglietti, 2004; Vicuna and Dracup, 2007; Wang et al., 2008; Peng and Xu, 2009). However, since the ecosystems particularly in the water-limited regions have high dependency on water, any slight changes in WY (e.g., statistically insignificant changes) could have substantial influences on water resources and cause high pressure to ecosystems (McCabe and Wolock 1997). In addition, the consistency of the trends of WY and $P$ also depended on the magnitude of WY. In arid areas where WY is negligible, the trend of WY may not follow that of $P$ given the balance between low $P$ and relatively high ET (Alkama et al., 2011).

\subsection{Spatial viability in long-term mean $W Y$}

The estimated mean annual ET of the various ecosystem types across the NSTEC ( $588 \mathrm{~mm}$ ) was comparable to the global average reported by other studies. For example, Mueller et al. (2011) and Zeng et al. (2012) reported global average ET for terrestrial ecosystems as $580-604 \mathrm{~mm}$ during similar time period as our study. The magnitude and spatial pattern of WY was also consistent with the basin-based streamflow measurements in the same region from 1971-1998 as reported by Milly et al. (2005). The increasing trends for both ET and WY from Ntemp to Ntrop reflected the dominant effect of $P$ over ET on the spatial pattern of WY (Zhang et al., 2009).

\subsection{Volumetric $W Y$ and land cover type}

It is well known that ET rates varied among vegetation types. ET of forests and wetlands can be as much as twice compared to other types of vegetation covers (Ellison et al., 2012). Our study predicted different ET rates and WY among LULC types. Our study also showed that the total volumetric WY for different LULC type was highly dependent on the area of its coverage. This somewhat contrasted to studies in the United States where 23\% forest land provided 43\% WY (2002-2007 mean) (Dr. Ge Sun, unpublished data, USDA Forest Service). The reason for the high WY in forest area of the U.S. was that the forests were mainly distributed in high altitude regions characterized with high $P$ but low $T$. Consequently, the relatively low ET compared to $P$ caused high WY. However the NSTEC had an mean elevation lower than $500 \mathrm{~m}$ (469.9 \pm $431.0 \mathrm{~m}$ ) and the mean elevation of the woodland areas in the NSTEC was not the highest among the LULC types (Fig. 5c). Unlike the U.S. where forest lands are widely distributed in the remote mountain areas, the NSTEC has been involved with intensive human disturbances and it has very complex LULC patterns. Thus WY of woodlands was not markedly different from other land uses.

\subsection{Sensitivity of $W Y$ to $P$ and $T$ changes along the latitudinal profile}

Labat et al. (2004) reported a $4 \%$ increase of global runoff in response to global $T$ increase per ${ }^{\circ} \mathrm{C}$. This is the first report on the test of global runoff trend using data-based evidence but it is questioned by other scholars (Legates et al., 2005). Preston and Jones (2008)'s study in Australia found that warming would reduce runoff with the magnitude up to $20 \%$. The signs of mean annual WY changes at the NSTEC in our study were also negative in the warming period from 1981 to 2000 but in a much lower rate of change. The higher sensitivity of $\mathrm{WY}$ to $P$ compared to $T$ variations reflected that WY or streamflow may respond to changes in $P$ in a highly nonlinear way, i.e., slight changes in $P$ might generate much greater changes in WY, double or even higher in some cases (Karl and Riebsame, 1989). For example, a $10 \%$ change in $P$ may result in a change of $20 \%$ in annual streamflow and $20 \%$ change in $P$ may result in a change of $45 \%$ in annual streamflow in a coastal watershed in North Carolina (Qi et al., 2009). They also found that streamflow was more sensitive to prescribed changes in $P$ than $T$ in this humid coastal watershed.

Along the latitudinal profile of the NSTEC, the sensitivity of WY to $T$ or $P$ change was negatively correlated with latitude. This result was in agreement with a theoretical study in the northwestern region of China by Ma et al. (2007) that WY responds more strongly to changes in $P$ and PET in the humid than the arid areas. One would expect that the differences in WY between the south and north of the NSTEC would be larger if future climate becomes colder and wetter. On the contrary, the differences in WY would be smaller if it becomes warmer and drier.

\subsection{Hydrological studies on terrestrial transects}

Transect survey is a common tool to study the spatial variation of water regime, such as soil moisture and water flux, but usually in small spatial scales, e.g., plot or local scale. Globally, studies on spatial variability of hydrological balance and its sensitivity to climate changes in large-scale terrestrial transects are still lacking, although transect method has advantages to resolve some particular questions such as examination of long-term equilibration or stationarity, identification of thresholds along a continuum and unification of ecological, atmospheric and climatic change models (Koch et al., 1995). Lare and Nicholson (1991) conducted an analysis of the mean surface hydrological balance for a latitudinal transect in West Africa. They found a substantial higher surface runoff in the wetter section of the transect due to excess precipitation, which is in agreement with the pattern of WY in the NSTEC. In China, there are two IGBP terrestrial transect including the NSTEC and the NECT (Northeast China Transact). Most previous studies conducted on these two transects are mainly on the spatial patterns of vegetation structure, primary productivity, carbon balance, nitrogen deposition, water/nutrient use efficiency and their relationships with the climate pattern (Zhou et al., 2002; Zhu et al., 2006; Zhang and Zhou, 2008; Sheng et al., 2011, 2012). This study represents the first effort to evaluate the spatial variability of hydrological balances and its response to climate change along the NSTEC profile.

\subsection{Uncertainties and limitations of this study}

Because our study is based on empirical modeling of ET and WY, uncertainties relating to input parameters exist. First of all, the 
accuracy of LULC classification could lead to inaccurate estimation of ET and WY. Although the CAS1990 production was the best in classification accuracy in a $1 \mathrm{~km}$ spatial resolution for China compared to the other popular LULC products such as GLC2000, IGBP-Discover and UMd (Ran et al., 2009), all these databases suffer varied problems and need improvements. Secondly, the temperature-based Hamon's PET equation calibrated for the early 20th century could be invalid in future climate conditions (Shaw and Riha, 2011). Thirdly, since the interactions between $P$ and ET may affect regional climate (Ellison et al., 2012), separating the effects of land cover change from climate change on the alterations of regional WY remains challenging (Feng et al., 2012). In our study, the spatial variability in WY across the NSTEC reflected the combined effects of $P$ and ET, the vegetation cover heterogeneity and associated changes in P-ET interactions in the scope of atmospheric circulation was not considered in the modeling approach.

The use of a constant $w$ value for each LULC type without considering vegetation evolution and its regional differences among years and across the entire region may also cause estimation errors for ET, and thus WY (Farley et al., 2005). The estimation of WY may have bias by using the un-calibrated $\mathrm{w}$ factor. We did not recalibrate $\mathrm{w}$ factor for all LULC types across the study region because: (1) The previous studies in China and the US (Sun et al., 2002, 2005,2006 ) suggest that the selected $w$ values were reasonable for regional mapping of water yield and detecting hydrological response to climate variability and land cover change. (2) The available 5-yr hydrological data for only ten basins were not sufficient to calibrate the model since these watersheds were large in size and had mixed land covers. Therefore, we focused on the evaluation of the model performance with hope that future small watershed or field scale studies can provide more reliable parameters. (3) Since our ultimate goal of this paper was to examine the trends and relative changes of $\mathrm{WY}$ as influenced by climate, systematic errors in $\mathrm{w}$ may not severely affect the final conclusions. Our statistical analysis indeed found such assumptiondeviation of $\mathrm{w}$ factor values from the default values caused small change in the trend and sensitivity of WY. (4) The hydrological trends detected by this study were affected by many factors other than LULC such as engineering dams, and human water consumption.

In this study, we used relatively short time series due to the availability of LULC data. The trend of WY may be different in prolonged period or shifted time windows as found for ET (Zeng et al., 2012). In addition, we considered only the effects of $T$ and $P$. Even they are two important aspects of climate, considering only these two factors is limited in understanding the future climate effects on hydrological processes (Rosenberg et al., 2003; Liu et al., 2012). For example, a recent modeling study in eastern China by Liu et al. (2012) suggests irrigation and other human-induced environmental stressors could have large impacts on the general hydrologic patterns regulated by the physical climate.

\section{Conclusions}

We examined water yield responses to climate change and variability at multiple scales across a large climatic gradient in eastern China. We conclude that the changes of the hydrologic regimes in the NSTEC in the past $20 \mathrm{yr}$ were dominated by precipitation, not by air temperature. Changes in precipitation masked the effects of climate warming. Water yield in Southern China is expected to be more responsive to climate change and variability, but any decline in water resources due to climate change in northern China can aggravate the current water crisis. Future distribution of water resources and their temporal changes would likely be influenced by the projected large variations in precipitation that is highly affected by the monsoon climate in China. Therefore, reliable projection of precipitation for eastern China is critical to hydrologic predictions and water resource planning.

This study represents the first effort to fully examine the current and future hydrologic balances across the large climatic gradient of the NSTEC by employing a modeling approach. Future studies need to examine the effects of other climatic variables, such as relative humidity, solar radiation and increased $\mathrm{CO}_{2}$ concentration as well as vegetation feedbacks on hydrological cycles. Models with a finer temporal scale (i.e., daily to monthly) are also desirable to capture the wide temporal dynamics of climate across the region.

\section{Acknowledgements}

We would like to thank the two anonymous reviewers for their constructive suggestions and comments. This study is financially supported by the National Basic Research Program of China (No. 2009CB421104), and the CAS/SAFEA International Partnership Program for Creative Research Teams of "Ecosystem Processes and Services". Partial support is also from the Southern Research Station of the USDA Forest Service.

\section{References}

Alkama, R., Decharme, B., Douville, H., Ribes, A., 2011. Trends in global and basinscale runoff over the late twentieth century: methodological issues and sources of uncertainty. J. Climate, 3000-3013.

Arnell, N.W., 1999. The effect of climate change on hydrological regimes in Europe: a continental perspective. Global Environ. Change 9, 5-23.

Barontini, S., Grossi, G., Kouwen, N., Maran, S., Scaroni, P., Ranzi, R., 2009. Impacts of climate change scenarios on runoff regimes in the southern Alps. Hydrol. Earth Syst. Sci. Discuss. 6, 3089-3141.

Bates, B.C., Kundzewicz, Z.W., Wu, S., Palutikof, J.P. (Ed.), 2008. Climate Change and Water. Technical Paper of the Intergovernmental Panel on Climate Change. IPCC Secretariat, Geneva, pp. 210.

Bing, L., Su, H., Shao, Q., Liu, J., 2012. Changing characteristic of land surface evapotranspiration and soil moisture in China during the past 30 years. J. GeoInform. Sci. 14 (1), 1-13 (in Chinese).

Blöschl, G., 2006. Hydrologic synthesis: across processes, places, and scales. Water Resour. Res. 42, W03S02. http://dx.doi.org/10.1029/2005WR004319.

Brutsaert, W., Parlange, M., 1998. Hydrologic cycle explains the evaporation paradox. Nature 396, 30.

Dang, H., Gillett, N.P., Weaver, A.J., Zwiers, F.W., 2007. Climate change detection over different land surface vegetation classes. Int. J. Climatol. 27, 211-220.

Davi, H., Dufrêne, E., Francois, C., Le Maire, G., Loustau, D., Bosc, A., Rambal, S. Granier, A., Moors, E., 2006. Sensitivity of water and carbon fluxes to climate changes from 1960 to 2100 in European forest ecosystems. Agric. Forest Meteorol. 141, 35-56.

Ellison, D., Futter, M.N., Bishop, K., 2012. On the forest cover-water yield debate: from demand-to supply-side thinking. Glob. Change Biol. 18, 806-820.

Farley, K.A., Jobbagy, E.G., Jackson, R.B., 2005. Effects of afforestation on water yield: a global synthesis with implications for policy. Glob. Change Biol. 11, 15651576. http://dx.doi.org/10.1111/j.1365-2486.2005.01011.x.

Federer, C.A., Lash, D., 1978. BROOK: A Hydrologic Simulation Model for Eastern Forested. Research Report 19. Water Resources Research Center, University of New Hampshire, Durham, NH, pp. 84.

Feng, X.M., Sun, G., Fu, B.J., Su, C.H., Liu, Y., Lamparski, H., 2012. Regional effects of vegetation restoration on water yield across the Loess Plateau, China. Hydrol. Earth Syst. Sci. Discuss. 9, 4261-4291 (in review).

Fernandes, R., Korolevych, V.K., Wang, S., 2007. Trends in land evapotranspiration over Canada for the period 1960-2000 based on in situ climate observations and a land surface model. J. Hydrometeorol. 8, 1016-1030. http://dx.doi.org/ 10.1175/JHM619.1.

Gao, G., Chen, D., Xu, C.Y., Simelton, E., 2007. Trend of estimated actual evapotranspiration over China during 1960-2002. J. Geophys. Res. 112, D11120. http://dx.doi.org/10.1029/2006JD008010.

Gordon, W.S., Famiglietti, J.S., 2004. Response of the water balance to climate change in the United States over the 20th and 21st centuries: results from the VEMAP phase 2 model intercomparisons. Global Biogeochem. Cycles 18 GB1030, http://dx.doi.org/10.1029/2003GB002098.

Hobbins, M.T., Ramirez, J.A., Brown, T.C., 2004. Trends in pan evaporation and actual evapotranspiration across the conterminous U.S.: paradoxical or complementary? Geophys. Res. Lett. 31, L13503. http://dx.doi.org/10.1029/ 2004GL019846, 2004

Huntington, T.G., 2006. Evidence for intensification of the global water cycle: review and synthesis. J. Hydrol. 319, 83-95. 
IPCC. 2007. Climate change 2007: Impacts, adaptation and vulnerability. In: Parry, M., Canziani, O, Palutikof, J., van der Linden, P., Hanson, C. (Eds.), Contribution of Working Group II to the Fourth Assessment Report of the Intergovernmental Panel on Climate Change. Cambridge University Press, Cambridge.

Jackson, R.B., Carpenter, S.R., Dahm, C.N., McKnight, D.M., Naiman, R.J., Postel, S.L., Running, S.W., 2001. Water in a changing world. Ecol. Appl. 11 (4), 1027-1045.

Jung, M., Reichstein, M., Ciais, P., Seneviratne, S.I., Sheffield, J., Goulden, M.L., Bonan G., Cescatti, A., Chen, J., de Jeu, R., et al., 2010. Recent decline in the global land evapotranspiration trend due to limited moisture supply. Nature 467, 951-954. http://dx.doi.org/10.1038/nature09396.

Karl, T.R., Riebsame, W.E., 1989. The impact of decadal fluctuations in mean precipitation and temperature on runoff: a sensitivity study over the United States. Clim. Change 15, 423-447.

Koch, G.W., Vitousek, P.M., Steffen, W.L., Walker, B.H., 1995. Terrestrial transects for global change research. Vegetatio 121, 53-65.

Labat, D., Goddéris, Y., Probst, J.L., Guyot, J.L., 2004. Evidence for global runoff increase related to climate warming. Adv. Water Resour., 631-642.

Lare, A.R., Nicholson, S.E., 1991. An analysis of the mean surface hydrological balance for a latitudinal transect in West Africa. Soil water balance in the Sudano-SaheUan Zone. In: Proceedings of the Niamey Workshop, February 1991. IAHS Publ. No. 199.

Legates, D.R., Lins, H.F., McCabe, G.J., 2005. Comments on "Evidence for global runoff increase related to climate warming" by Labat et al.. Adv. Water Resour. 28 , 1310-1315.

Liu, C.M., Xia, J., 2004. Water problems and hydrological research in the Yellow River and the Huai and Hai River basins of China. Hydrol. Process. 18, $2197-$ 2210.

Liu, Q., Yang, Z.F., 2010. Quantitative estimation of the impact of climate change on actual evapotranspiration in the Yellow River Basin, China. J. Hydrol. 395, 226 234.

Liu, M., Tian, H., Lu, C., Xu, X., Chen, G., Ren, W., 2012. Effects of multiple environment stresses on evapotranspiration and runoff over eastern China. J. Hydrol. 426-427, 39-54.

López-Moreno, J.I., Vicente-Serrano, S.M., Moran-Tejeda, E., Zabalza, J., LorenzoLacruz, J., García-Ruiz, J.M., 2011. Impact of climate evolution and land use changes on water yield in the Ebro basin. Hydrol. Earth Syst. Sci. 15, 311-322.

Lu, J., Sun, G., Amatya, D.M., McNulty, S.G., 2003. Modeling actua evapotranspiration from forested watersheds across the Southeastern United States. J. Am. Water Resour. Assoc. 39 (4), 887-896.

Lu, N., Wilske, B., Ni, J. John, R., Chen, J., 2009. Climate change in Inner Mongolia from 1955 to 2005 - trends at regional, biome and local scales. Environ. Res. Lett. 4, 045006. http://dx.doi.org/10.1088/1748-9326/4/4/045006.

Ma, Z., Kang, S., Zhang, L., Tong, L., Su, X., 2007. Analysis of impacts of climate variability and human activity on streamflow for a river basin in arid region of northwest China. J. Hydrol. 352, 239-249.

McCabe Jr., G.J., Wolock, D.M., 1997. Climate change and the detection of trends in annual runoff. Climate Res. 8, 129-134.

Meehl, G.A., Stocker, T.F., Collins, W.D., Friedlingstein, P., Gaye, A.T., Gregory, J.M., Kitoh, A., Knutti, R., Murphy, J.M., Noda, A., et al., 2007. Global climate projections. In: Solomon, S. et al. (Eds.), Climate Change 2007: The Physica Science Basis. Cambridge University Press, Cambridge, United Kingdom and New York, NY, USA

Milly, P.C.D., Dunne, K.A., Vecchia, A.V.V., 2005. Global pattern of trends in streamflow and water availability in a changing climate Nature 438, 347-350.

Mueller, B., Seneviratne, S.I., Jimenez, C., Corti, T., Hirschi, M., Balsamo, G., Ciais, P., Dirmeyer, P., Fisher, J.B., Guo, Z., et al., 2011. Evaluation of global observationsbased evapotranspiration datasets and IPCC AR4 simulations. Geophys. Res. Lett. 38, L06402. http://dx.doi.org/10.1029/2010GL046230.

Piao, S., Ciais, P., Huang, Y., Shen, Z., Peng, S., Li, J., Zhou, L., Liu, H., Ma, Y., Ding, Y., et al., 2010. The impacts of climate change on water resources and agriculture in China. Nature 467, 43-51. http://dx.doi.org/10.1038/nature09364.

Peng, D., Xu, Z., 2009. Simulating the impact of climate change on streamflow in the Tarim River basin by using a modified semi-distributed monthly water balance model. Hydrol. Process.. http://dx.doi.org/10.1002/hyp. 7485.

Climatological Atlas of the Peoples' Republic of China. 1979. China Map Publisher, Beijing. (P469.2).

Peterson, T.C., Golubev, V.S., Groisman, P.Y.A., 1995. Evaporation losing its strength Nature 377, 687-688. http://dx.doi.org/10.1038/377687b0.

Preston, B.L., Jones, R., 2008. A national assessment of the sensitivity of Australian runoff to climate change. Atmos. Sci. Lett.. http://dx.doi.org/10.1002/asl.188.

Qi, S., Sun, G., Wang, Y., McNulty, S.G., Moore Myers, J.A., 2009. Streamflow response to climate and land use changes in a coastal watershed in North Carolina. Trans. ASABE 52 (3), 739-749.
Qiu, X., Liu, C., Zeng, Y., 2003. Changes of pan evaporation in the recent 40 years over the Yellow River basin. J. Natural Resour. 18 (4), 437-442.

Ran, Y., Li, X., Lu, L., 2009. Accuracy evaluation of the four remote sensing based land cover products over China. J. Glaciol. Geocryol. 3, 490-500.

Ren, G., Guo, J., 2006. Change in pan evaporation and the influential factors over China: 1956-2000. J. Natural Resour. 21 (1), 31-44.

Rosenberg, N.J., Brownb, R.A., Izaurralde, R.C., Thomsona, A.M., 2003. Integrated assessment of Hadley Centre (HadCM2) climate change projections on agricultural productivity and irrigation water supply in the conterminous United States I. Climate change scenarios and impacts on irrigation water supply simulated with the HUMUS model. Agric. Forest Meteorol. 117, 73-96.

Serrat-Capdevila, A., Scott, R.L., Shuttleworth, W.J., Valdés, J.B., 2011. Estimating evapotranspiration under warmer climates: Insights from a semi-arid riparian system. J. Hydrol. 399, 1-11.

Shaw, S.B., Riha, S.J., 2011. Assessing temperature-based PET equations under a changing climate in temperate, deciduous forests. Hydrol. Process. 25, 14661478.

Sheng, W., Ren, S., Yu, G., Fang, H., Jiang, C., Zhang, M., 2011. Patterns and driving factors of WUE and NUE in natural forest ecosystems along the north-south transect of Eastern China. J. Geogr. Sci. 21 (4), 651-665.

Sheng, W., Yu, G., Jiang, C., Yan, J., Liu, Y., Wang, S., Wang, B., Zhang, J., Wang, C., Zhou, M., Jia, B., 2012. Monitoring nitrogen deposition in typical forest ecosystems along a large transect in China. Environ. Monit. Assess., http:// dx.doi.org/10.1007/s10661-012-2594-0.

Sun, G., McNulty, S.G., Moore, J.M., Bunch, C., Ni, J., 2002. Potential impacts of climate change on rainfall erosivity and water availability in China in the next 100 Years. In: The Proceedings of the 12th International Soil Conservation Conference, Beijing China, May 2002.

Sun, G., McNulty, S.G., Lu, J., Amatya, D.M., Liang, Y., Kolka, R.K., 2005. Regional annual water yield from forest lands and its response to potential deforestation across the southeastern United States. J. Hydrol. 308, 258-268.

Sun, G., Zhou, G., Zhang, Z., Wei, X., McNulty, S.G., Vose, J.M., 2006. Potential water yield reduction due to forestation across China. J. Hydrol. 328, 548-558.

Sun, G., Alstad, K., Chen, J.Q., Chen, S.P., Ford, C.R., Lin, G.H., Liu, C.F., Lu, N., McNulty, S.G., Miao, H.X., Noormets, A., Vose, J.M., Wilske, B., Zeppel, M., Zhang, Y., Zhang, Z.Q., 2011. A general predictive model for estimating monthly ecosystem evapotranspiration. Ecohydrology 4, 245-255.

Todd, M.C., Taylor, R.G., Osborne, T., Kingston, D., Arnell, N.W., Gosling, S.N., 2010. Quantifying the impact of climate change on water resources at the basin scale on five continents - a unified approach. Hydrol. Earth Syst. Sci. Discuss. 7, 74857519.

Vicuna, S., Dracup, J.A., 2007. The evolution of climate change impact studies on hydrology and water resources in California. Clim. Change 82, 327-350.

Wagener, T., Sivapalan, M., Troch, P.A., McGlynn, B.L., Harman, C.J., Gupta, H.V. Kumar, P., Rao, S.C., Basu, N.B., Wilson, J.S., 2010. The future of hydrology: an evolving science for a changing world. Water Resour. Res. 46, W05301. http:// dx.doi.org/10.1029/2009WR008906.

Wang, S., Zhang, Z., Sun, G., McNulty, S.G., Zhang, H., Li, J., Zhang, M., 2008. Longterm streamflow response to climate variability in the loess plateau, China. J. Am. Water Resour. Assoc. 44 (5), 1098-1107.

Zeng, Z., Piao, S., Lin, X., Yin, G., Peng, S., Ciais, P., Myneni, R.B., 2012. Global evapotranspiration over the past three decades: estimation based on the water balance equation combined with empirical models. Environ. Res. Lett. 7, 014026. http://dx.doi.org/10.1088/1748-9326/7/1/014026.

Zhang, Y., Zhou, G., 2008. Terrestrial transect study on driving mechanism of vegetation changes. Sci. China Ser. D 51 (7), 984-991.

Zhang, L., Dawes, W.R., Walker, G.R., 2001. Response of mean annual evapotranspiration to vegetation changes at catchment scale. Water Resour. Res. 37, 701-708.

Zhang, K., Kimball, J.S., Mu, Q., Jones, L.A., Geotz, S.J., Running, S.W., 2009. Satellite based analysis of northern ET trends and associated changes in the regional water balance from 1983 to 2005. J. Hydrol. 379, 92-110.

Zhou, G., Wang, Y., Jiang, Y., Xu, Z., 2002. Carbon balance along the Northeast China transect (NECT-IGBP). Sci. China Ser. C 45, 18-29.

Zhou, L., Wang, S., Cheng, J., Feng, X., Ju, W., Wu, W., 2009. The spatial-temporal characteristics of evapotranspiration of China's terrestrial ecosystems during 1991-2000. Resour. Sci. 31, 962-972.

Zhu, W., Pan, Y., Liu, X., Wang, A., 2006. Spatio-temporal distribution of net primary productivity along the northeast China transect and its response to climatic change. J. Forestry Res. 17 (2), 93-98. 